\title{
ERYTHROCYTE OSMOTIC FRAGILITY TEST AS THE MEASURE OF DEFENCE AGAINST FREE RADICALS IN RABBITS OF DIFFERENT AGE
}

\author{
Ewa BRZEZIŃSKA-ŚLEBODZIŃSKA* \\ Department of Hormonal Action Mechanisms, Institute of Animal Reproduction and \\ Food Research of the Polish Academy of Sciences in Olsztyn, ul. Grunwaldzka 250, \\ 60-166 Poznań, Poland
}

(Received May 7, 2001; accepted September 5, 2001)

\begin{abstract}
Peroxidation of the unsaturated bonds of membrane lipids increases fragility and cellular lysis of red blood cells. Erythrocyte susceptibility to the free radicals (peroxyl radicals) generated in vitro by 2,2 '-azo-bis(2-amidinopropane) hydrochloride (AAPH) was evaluated and expressed as 50\% maximal haemolysis time $\left(\mathrm{HT}_{50}\right)$ in 3 groups of rabbits of different age. Erythrocytes of 1.5-month-old rabbits were more sensitive to free radicals than those of 3.5- and 6-month-old ones. In the three groups, significant negative correlation ( $r=-0.8$ to -0.98$)$ between the lipid peroxidation rate (thiobarbituric acid reactive substances; TBARS concentration) in blood plasma and the erythrocyte resistance to free radicals was found. This result suggests that the plasma antioxidant defence system is interrelated with that of the red blood cells and that the erythrocytes can be a good model for studies of oxidative stress. The simple haemolysis test reflecting the free radical defence can be useful for evaluating the antioxidant properties of various compounds.
\end{abstract}

Key words: Erythrocyte, free radicals, oxidative stress, lipid peroxidation

Oxidative stress results from an imbalance between the effect of prooxidants and the antioxidant defence mechanisms of the body. Mammalian red blood cells (RBC) are particularly susceptible to oxidative damage because: (1) being oxygen carrier, they are exposed uninterruptedly to high oxygen tension, (2) they have no capacity to repair their damaged components, and (3) their membrane components are susceptible to lipid peroxidation (LPO) (Galleano and Puntarulo, 1995). The oxidative modification of the membrane increases fragility of the RBC (Stern, 1986; Wagner et al., 1988). Under normal conditions, RBC rich in catalase, superoxide dismutase, glutathione, glutathione reductase, glutathione peroxidase and a proteolytic system that can hydrolyse oxidativelymodified proteins (Halliwell and Gutteridge, 1989), are capable of preventing most of the adverse effects of oxidative stress (Gutteridge, 1994). Vitamin E ( $\alpha$ -

*E-mail: endocrin@rose.man.poznan.pl; Fax: +48 (1033) 61-868-53-28 
tocopherol), an extremely effective antioxidant when incorporated into the membrane (Gutteridge, 1978), and melatonin when taken up into human erythrocytes under oxidative stress (Tesoriere et al., 1999), strongly enhance RBC resistance to oxidative lysis. These lytic processes can be evaluated by measuring the free radical-induced $\mathrm{RBC}$ haemolysis and utilised to assess the antioxidant properties of natural compounds or drugs including urate, ascorbate, tocopherol, butylated hydroxytoluene and probucol (Blache et al., 1991). One of the advantages of this haemolysis test is the possibility to monitor ex vivo the time course effects of a supplementation with various antioxidants (Velasquez-Pereira et al., 1998).

Plasma transferrin and lactoferrin themselves act as antioxidants by binding iron ions (Gutteridge et al., 1981). The plasma copper-containing protein ceruloplasmin plays an essential role in the process. It has a ferrooxidase-activity and oxidases ferrous ions to the less reactive ferric state while reducing oxygen to water, thereby inhibiting iron-dependent LPO (Gutteridge et al., 1980). The ceruloplasmin-catalysed oxidation of ferrous ions does not release any damaging oxygen radicals, as they are kept on the active site of the protein (Gutteridge and Stocks, 1981). Plasma albumin binds copper ions and inhibits copper ion-dependent LPO and hydroxyl radical formation (Gutteridge, 1986). Copper ions can attach SHgroups on the membranes of erythrocytes and facilitate their oxidative damage.

Several methods currently exist for estimating the LPO (for review see Halliwell and Grootveld, 1987). Based on the reaction of malondialdehyde (MDA), a breakdown product of lipid peroxides, with thiobarbituric acid, the measurement of thiobarbituric acid reactive substances (TBARS) has been commonly used to check the products of LPO (Hessler et al., 1983). Although some reports suggest that MDA is an artefact of the TBARS procedure, in most of the biological systems it is a genuine product of LPO (Slater and Cheeseman, 1988).

In the present study erythrocyte susceptibility to oxidative stress was evaluated in vitro by submitting cells to an organic free radical generator. To examine the relationship between erythrocyte osmotic fragility and plasma antioxidant defence, the erythrocyte resistance against free radicals and the LPO endproduct malondialdehyde were determined in plasma by the thiobarbituric-acid assay.

\section{Materials and methods}

Animals

The experiments were performed on White New Zealand rabbits aged 1.5, 3 and 6 months $(n=30)$ and bred in our laboratory. The animals were kept in separate metal cages at a room temperature around $20^{\circ} \mathrm{C}$ and exposed to a $10: 14$ light-dark cycle. They were provided with commercial pellets for rabbits and drinking water ad libitum. Blood was collected with heparin to provide erythrocytes and plasma, placed on ice and transported to the laboratory. 


\section{Reagents}

1,1,3,3-Tetraethoxypropane (MDA, an external standard), trichloroacetic acid, thiobarbituric acid and n-butanol were purchased from Sigma Chemical Co. (St. Louis, MO, USA), and 2,2'-azobis(2-amidinopropane)hydrochloride (AAPH) from Polysciences (Warrington, PA, USA).

\section{Erythrocyte susceptibility to free radicals}

Susceptibility of erythrocytes to free radicals generated in vitro was evaluated as described by Girodon et al. (1997). Erythrocytes were isolated by centrifugation of heparinised blood for $10 \mathrm{~min}$ at $2000 \times \mathrm{g}$ at $4{ }^{\circ} \mathrm{C}$, then the plasma was pipetted out, the RBCs were washed three times with $0.15 \mathrm{M} \mathrm{NaCl}$ and resuspended at $15 \%$ haematocrit with $0.15 \mathrm{M} \mathrm{NaCl}$. Washed erythrocyte suspensions were exposed to peroxyl radical generated by decomposition of $0.15 \mathrm{M}$ AAPH at $37^{\circ} \mathrm{C}$ for 4 to $4.5 \mathrm{~h}$. At 30 -min intervals, $0.02 \mathrm{ml}$ of the incubation mixture was diluted 200 times with $0.15 \mathrm{M} \mathrm{NaCl}$ and centrifuged at $9000 \times \mathrm{g}$ for $1 \mathrm{~min}$. The released haemoglobin content of the supernatant was evaluated by measuring the absorbance at $405 \mathrm{~nm}$ against $0.15 \mathrm{M} \mathrm{NaCl}$. Results were expressed as $50 \%$ of maximal haemolysis time ( $\mathrm{HT}_{50}$ in minutes), using the sigmoidal Boltzmann curve plotted and fitted for each animal by GraphPad Prism computer programme for nonlinear regression.

\section{Assay of thiobarbituric acid reactive substances (TBARS) in plasma}

The amount of TBARS in plasma was determined by the method of Ledwożyw et al. (1986) and expressed in MDA. In short, $0.25 \mathrm{ml}$ sample was mixed with $1.25 \mathrm{ml}$ of $1.22 \mathrm{M}$ trichloroacetic acid in $0.6 \mathrm{M} \mathrm{HCl}$ and allowed to stand for $15 \mathrm{~min}$. To this mixture $0.75 \mathrm{ml}$ of thiobarbituric acid solution was added (obtained by dissolving $500 \mathrm{mg}$ thiobarbituric acid in $6 \mathrm{ml}$ of $1 \mathrm{M} \mathrm{NaOH}$ then adding $69 \mathrm{ml} \mathrm{H}_{2} \mathrm{O}$ ) and heated for $30 \mathrm{~min}$ at $100{ }^{\circ} \mathrm{C}$ in an electric heater. After cooling to room temperature $2 \mathrm{ml}$ of n-butanol was added, the mixture was shaken vigorously for $3 \mathrm{~min}$ and centrifuged for $20 \mathrm{~min}$ at $2000 \times \mathrm{g}$. The organic layer, containing the lipid peroxidation end-products, was removed and its absorbance was measured at $532 \mathrm{~nm}$ against blank. The results were expressed as nmoles of MDA/1 ml of plasma using 1,1,3,3-tetramethoxypropane as standard. Standard curve was made of MDA solution in concentrations ranging from 2.5 to $50.0 \mu \mathrm{M}$.

\section{Statistical analysis}

The data were analysed for differences by Student's $t$-test. A difference was considered significant at $\mathrm{P}<0.05$. 


\section{Results}

The erythrocytes of 1.5 -month-old rabbits were more sensitive to free radical damage than those of 3.5- and 6-month-old ones (Fig. 1). $\mathrm{HT}_{50}$ values for these three groups of age were $133.0 \pm 2.42 \mathrm{~min}, 144.0 \pm 2.49 \mathrm{~min}$ and $186.0 \pm$ 7.5 min, respectively $(\mathrm{P}<0.01-0.001)$. TBARS content in plasma, expressed as the lipid peroxidation end-product MDA concentration, decreased significantly $(\mathrm{P}<0.001)$ with advancing rabbits age from $10.2 \pm 0.19$ in 1.5 -month-old to $6.2 \pm 0.31 \mathrm{nmol} / 1 \mathrm{ml}$ in 6-month-old animals.

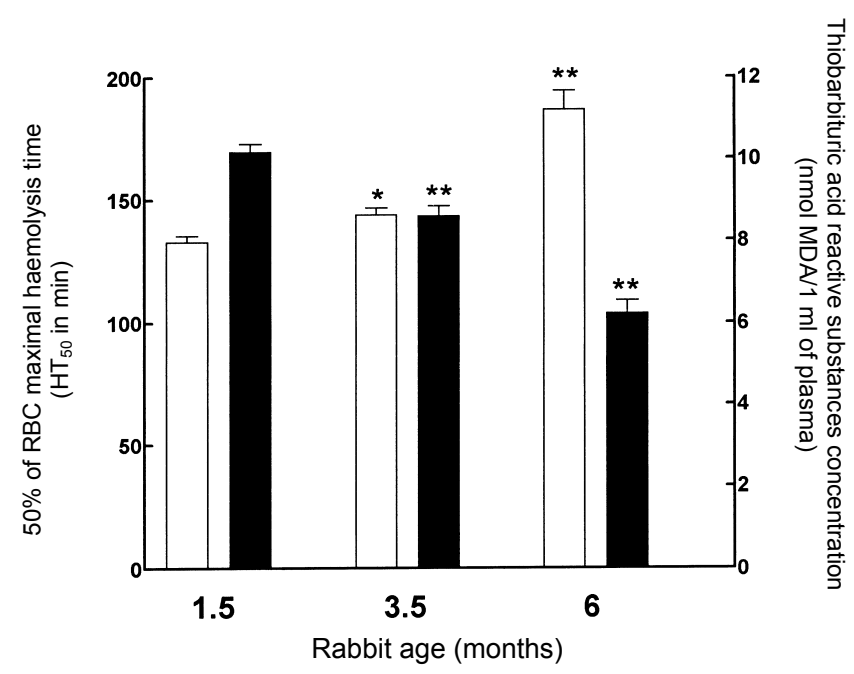

Fig. 1. The $\mathrm{HT}_{50}$ values (open bars) and TBARS concentrations (black bars) of the different age groups of rabbits $\left(\mathrm{n}=10\right.$ in each group). Mean values $\pm \mathrm{SEM} ;{ }^{*} \mathrm{P}<0.01 ;{ }^{* *} \mathrm{P}<0.001$

Significant $(\mathrm{P}<0.01-0.001)$ negative correlations between the rate of lipid peroxidation in the plasma and erythrocyte resistance to free radicals were found in all groups of animals ( $\mathrm{r}=$ from -0.80 to -0.98 ; Fig. 2 ).

\section{Discussion}

The free radical generator (AAPH) used in the present studies was an azocompound which thermally decomposed and gave carbon-centred peroxyl radicals and nitrogen. In the presence of air oxygen, peroxyl radicals are produced at a constant rate (Tereo and Niki, 1986). The radicals can abstract hydrogen and peroxidise a lipid substrate, namely linoleic acid and linoleate ester. The utility of this procedure was proven to be useful to assess total antioxidative status as it is not only sensitive to membrane vitamin $\mathrm{E}$ and glutathione depletion but also to inhibi- 
tion of catalase or glutathione peroxidase (Blache et al., 1991; Girodon et al., 1997). In other tests which have been developed for the measurement of the antioxidant activity of biological fluids, procedures vary as to the free radical generator utilised and to the reproducibility of the generation process. One of the employed procedures is the total radical-trapping potential (TRAP) method developed by Wayner et al. (1985). It uses AAPH as the free radical generator, but this method requires specific oxygen electrode and has limited physiological relevance of AAPH-derived peroxyl radicals (Halliwell and Gutteridge, 1990). Methods devoted to erythrocyte susceptibility to oxidative stress conducted with $\mathrm{H}_{2} \mathrm{O}_{2}$ or other generators in the presence of a catalase inhibitor measure the rate of lipoperoxidation, the cell deformability or the amount of haemoglobin released (Girodon et al., 1997). The AAPH generator is superior to $\mathrm{H}_{2} \mathrm{O}_{2}$ because it does not need catalase inhibitor (such as azide) and because peroxyl radicals are produced at a known and constant rate (Yamamoto et al., 1986) which results in a low variability (Girodon et al., 1997).
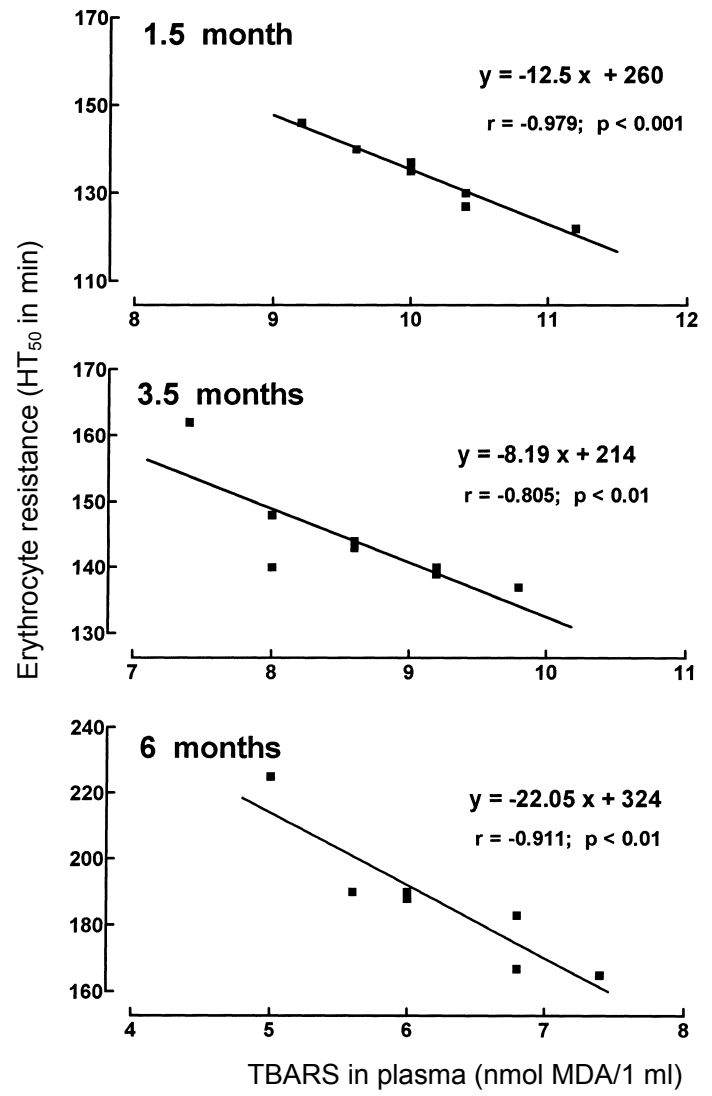

Fig. 2. Correlations between TBARS concentration of the blood plasma and the resistance of erythrocytes to free radicals 
The present study shows that the RBC susceptibility to free radicals is influenced by the age of the animals (Fig. 1). The erythrocytes of young rabbits (1.5 months old) were less resistant to free radical damage than those of older animals. Using the free radical-induced haemolysis test, Girodon et al. (1997) compared the oxidative damage in young (42 years old) and elderly ( $>65$ years) humans. In elderly subjects, the RBC antioxidant defence was reduced and could be improved with antioxidants (vitamins $\mathrm{C}$ and $\mathrm{E}, \beta$-carotene) supplementation. These antioxidants were also beneficial in improving the erythrocyte osmotic fragility in rats (Kraus et al., 1997a,b).

As shown in Fig. 2, a significant correlation between erythrocyte susceptibility to free radicals and the rate of LPO (TBARS level) in plasma exists within each group of age. The TBARS assay, as an index of free radical degradation of polyunsaturated fatty acids measures two main products: malondialdehyde and 4-hydroxynonenal (Reiter, 1995). This aldehyde can cause cross-linking of lipids, proteins and nucleic acid (Freeman and Crapo, 1982; Flohe et al., 1985).

Our results confirm the suggestion of Stocker and Frei (1991) that plasma antioxidant defence is interrelated with that of the RBC, as illustrated by variation in $\mathrm{RBC} \mathrm{HT}_{50}$ against the plasma TBARS level. The $\mathrm{HT}_{50}$ is influenced more by chain-breaking antioxidants than by iron-oxidising or iron-binding antioxidants in plasma (Brzezińska-Ślebodzińska, unpublished data). This result suggests that the plasma chain-breaking antioxidants may reflect the amount of the same antioxidants of the erythrocyte membrane, which most likely provides primary protection against haemolysis induced by peroxyl radicals.

\section{References}

Blache, D., Prost, M. and Raffi, J. (1991): In vitro biological test of resistance to oxidation: application to identification of irradiated food. In: Potential New Methods of Detection of Irradiated Food. Luxembourg Commission of the European Communities, pp. 105-116.

Flohe, L., Beckmann, R., Giertz, H. and Loschen, G. (1985): Oxygen-centered free radicals as mediators of inflammation. In: Sies, H. (ed.) Oxidative Stress. Academic Press, New York, pp. 405-437.

Freeman, B. A. and Crapo, J. D. (1982): Biology of disease: free radicals and tissue injury. Lab. Invest. 47, 412-426.

Galleano, M. and Puntarulo, S. (1995): Role of antioxidants on the erythrocytes resistance to lipid peroxidation after acute iron overloads in rats. Bioch. Biophys. Acta 1271, 321-326.

Girodon, F., Blache, D., Monget, A-L., Lombart, M., Brunet-Lecompte, P., Arnaud, J., Richard, M-J. and Galan, P. (1997): Effect of a two-year supplementation with low doses of antioxidant vitamins and/or minerals in elderly subjects on levels of nutrients and antioxidant defense parameters. J. Am. Coll. Nutr. 16, 357-365.

Gutteridge, J. M. C. (1978): The membrane effects of vitamin E, cholesterol and their acetates on peroxidative susceptibility. Res. Commun. Chem. Pathol. Pharm. 22, 563-571.

Gutteridge, J. M. C. (1986): Antioxidant properties of the proteins caeruloplasmin, albumin and transferrin. A study of their activity in serum and synovial fluid from patients with rheumatoid arthritis. Biochim. Biophys. Acta 969, 119-127.

Gutteridge, J. M. C. (1994): Biological origin of free radicals, and mechanisms of antioxidant protection. Chem.-Biol. Interact. 91, 133-140. 
Gutteridge, J. M. C. and Stocks, J. (1981): Ceruloplasmin: physiological and pathological perspectives. CRC Crit. Rev. Clin. Lab. Med. 14, 257-329.

Gutteridge, J. M. C., Paterson, S. K., Segal, A. W. and Halliwell, B. (1981): Inhibition of lipid peroxidation by the iron-binding protein lactoferrin. Biochem. J. 199, 259-261.

Gutteridge, J. M. C., Richmond, R. and Halliwell, B. (1980): Oxygen free radicals and lipid peroxidation: inhibition by the protein caeruloplasmin. FEBS Lett. 112, 269-272.

Halliwell, B. and Grootveld, M. (1987): The measurement of free radical reactions in humans. FEBS Letters 213, 9-14.

Halliwell, B. and Gutteridge, J. M. C. (1989): Free Radicals in Biology and Medicine. 2nd ed., Clarendon Press, Oxford, pp. 188-276.

Halliwell, B. and Gutteridge, J. M. C. (1990): The antioxidants of human extracellular fluids. Arch. Bioch. Biophys. 280, $1-8$.

Hessler, J. R., Morel, D. W., Lewis, L. J. and Chisolm, G. M. (1983): Lipoprotein oxidation and lipoprotein-induced cytotoxicity. Arteriosclerosis 3, 215-222.

Kraus, A., Roth, H.-P. and Kirchgessner, M. (1997a): Supplementation with vitamin C, vitamin E or $\beta$-carotene influences osmotic fragility and oxidative damage of erythrocytes of zincdeficient rats. J. Nutr. 127, 1290-1296.

Kraus, A., Roth, H.-P. and Kirchhessner, M. (1997b): Influence of antioxidants (vitamin C, vitamin $\mathrm{E}$ and $\beta$-carotene) on the osmotic fragility and components of the primary antioxidant system of erythrocytes in zinc-deficient rats. Trace Elem. Elec. 14, 30-37.

Ledwożyw, A., Michalak, J., Stępień, A. and Kądziołka, A. (1986): The relationship between plasma triglycerides, cholesterol, total lipids and lipid peroxidation products during human atherosclerosis. Clin. Chim. Acta 155, 175-184.

Reiter, R. J. (1995): Oxidative processes and antioxidative defense mechanisms in the aging brain. FASEB J. 9, 526-533.

Slater, T. F. and Cheeseman, K. H. (1988): Free radical mechanisms of tissue injury and mechanisms of protection. In: Quintanilha, A. (ed.) Reactive Oxygen Species in Chemistry, Biology, and Medicine. Plenum Press, New York, pp. 1-14.

Stocker, R. and Frei, B. (1991): Oxidants and antioxidants. In: Sies, H. (ed.) Oxidative Stress. Academic Press, London UK, pp. 213-243.

Stern, A. (1986): Red cell oxidative damage. In: Sies, H. (ed.) Oxidative Stress. Academic Press, London, UK, pp. 331-349.

Tereo, K. and Niki, E. (1986): Damage to biological tissues induced by radical initiator 2,2'azobis(2-amidinopropane) dihydrochloride and its inhibition by chain-breaking antioxidants. J. Free Radicals Biol. Med. 2, 193-201.

Tesoriere, L., D’Arpa, D., Conti, S., Giaccone, V., Pintaudi, A. M. and Livrea, M. A. (1999): Melatonin protects human red blood cells from oxidative hemolysis: new insight into the radical-scavenging activity. J. Pineal Res. 27, 95-105.

Velasquez-Pereira, J., McDowell, L. R., Risco, C. A., Prichard, D., Martin, F. G., Calhoun, M. C., Williams, S. N., Wilkinson, N. S. and Ogebe, P. (1998): Effects of performance, tissue integrity, and metabolism of vitamin E supplementation for beef heifers fed a diet that contains gossypol. J. Anim. Sci. 76, 2871-2884.

Wagner, G. M., Lubin, B. H. and Chiu, D. T-Y. (1988): Oxidative damage to red blood cells. In: Chow, C. K. (ed.) Cellular Antioxidant Defense Mechanisms. CRC Press Inc., Boca Raton, USA, vol. 1, pp. 185-195.

Wayner, D. D. M., Burton, G. W., Ingold, K. U. and Locke, D. (1985): Quantitative measurement of the total peroxyl radical trapping antioxidant capacity of human blood plasma by controlled lipid peroxidation. FEBS Lett. 187, 33-37.

Yamamoto, Y., Niki, E., Kamiya, Y., Miki, M., Tamai, H. and Mino, M. (1986): Free radical chain oxidation and hemolysis of erythrocytes by molecular oxygen and their inhibition by vitamin E. J. Nutr. Sci. Vitaminol. 32, 475-479. 